\title{
Investigating Unconventional Abbreviations In Sms Texts
}

\author{
Faustina Amponsah Partey*, Rosemary Gifty Addo-Danquah, Lucy Korkoi Bonku, Kwasi Sarfo-Adu \\ Department of Liberal Studies, Kumasi Technical University, Kumasi. Ghana
}

Corresponding Author: Faustina Amponsah-Partey, E-mail: tinapartey14@yahoo.com

\section{ARTICLE INFO}

Article history

Received: January 16, 2018

Accepted: March 09, 2018

Published: July 01, 2018

Volume: 7 Issue: 4

Advance access: May 2018

Conflicts of interest: None

Funding: None

\begin{abstract}
Abbreviations are intended to facilitate expeditious writing and make use of reduced space either on paper, the computer or the phone. Abbreviations have been used for quite a prolonged period and are putative wherever their use is effected. Nevertheless, over a period of time, some unconventional abbreviations seemed to be slithering into the literatures of students of Kumasi Technical University, Kumasi, Ghana where the study was conducted. This article has been aggravated by my incessant observance of the frequency at which unconventional abbreviations are used by Kumasi Technical University students in their Short Message Service (SMS) texts to others. Consequently, this paper strives to unearth the varieties of unconventional abbreviations used by these students and analyze them linguistically and phonologically. A corpus of 300 SMS texts was then assembled from five departments but 200 were purposively sampled for the analysis; and with Anjaneyulu's (2003) five methods of generating shortened words in SMS as the basis of the analysis, the results revealed a preponderance of unconventional abbreviations constituting $60 \%$ of the data compiled. The most frequently striking category of abbreviations involved maximum use of letters, symbols, or figures to produce the appropriate phonetic sound, adhoc abbreviations and a negligible or barest use of alphanumeric or hybrid method. These arguably connote an appreciation of phonology where the sounds of the words are what the students use to structure their abbreviations.
\end{abstract}

Key words: Abbreviations, Unconventional, Alphanumeric, Short Message Service

\section{INTRODUCTION}

The use of cell phones or mobile phones has become very extensive and tower above most conversations on college campuses and in tertiary institutions. A prodigious number of students are getting profoundly involved in matters of texting (even during lectures) and this is causing quite some trepidation and panic for a lot of parents, educators, teachers and all stakeholders of education. This concern pungently arises because of the apprehension that good writing skills, more importantly, spelling would not be adhered to and that would affect proficiency in English Language. New linguistic features specific to the mobile phone have been embraced and used on the platform of texting. This has resulted in an escalating increase in the use of informal or unconventional written language, inconsistency in the writing styles and stylistics and the use of newly coined and created abbreviations. According to Singh et al (2015), originally text messages were to be operated within a threshold of 120 characters which forced users to make a more economical mode of communication while Barkhaus and Vallgarda (2004) are of the opinion that despite the 160 character limit on SMS which the sender is obligated to use, over 5 million text messages in 2001 were sent by the Scandina- vian countries alone. Consequently, a substantial number of young people especially, have fashioned out their own abbreviations for pragmatic reasons, in order to put to effective maximum use of the diminutive time, space available and effort needed to communicate with others.

A lot of uneasiness has been expressed by the stakeholders aforementioned in that in no time the English Language would be subjugated by SMS language. The modifications we see taking place today in the English Language will be a prelude to the gradual dying use of good English(Sun, April 24, 2001). Another concern raised is from Observer (March 7, 2004) that the English Language is being crushed over time and civilization is in danger of crumbling. While some people are of the opinion that the contemporary situation of hyping the deleterious effects of SMS language per the English Language will either dwindle or develop into a new language to be used among those who can decode them, others strongly believe the distinct orthography used by these texters will certainly muddle standards of spelling and grammar. Therefore, the research questions this paper seeks to find answers to is to examine the varieties of unconventional abbreviations used by students of Kumasi Technical University and the linguistic and phonological affiliations these abbreviations have with formal English Language 
usage. Another question is to discover the factors that push these students into using the unconventional abbreviations.

This paper aims at taking a painstaking and analytical investigation into the abbreviations used by students of $\mathrm{Ku}-$ masi Technical University in their SMS text messages and to reconnoiter the frequency of the self- created abbreviations in these messages while centering attention on the linguistic and phonological aspects of the abbreviations.

\section{Abbreviations in SMS}

Usage of abbreviations is another approach to addressing the issue of limited number of characters in each SMS message. There are five ways of generating shortened words in SMS (Anjaneyulu, 2013).According to him, these ways or methods are (i) the use of traditional (known) or adhoc abbreviation eg, mins - minutes;(ii) dropping a single letter eg, rite for write; (iii) the use of letters, symbols or numbers to make the appropriate phonetic sound eg, gr8 for 'great'; (iv) the use of standard or adhoc acronyms eg, w-with; and finally (v), the use of hybrid method eg, b4 for before.

World English Dictionary (2009) elucidates that an abbreviation is a shortening of a word or phrase that is to be used to report the full form. According to the studies of linguistics, there are mainly four kinds of abbreviations. They are Shortenings, Contractions, Initialisms, and Acronyms.

Shortenings are words or phrases usually consisting of the first letters of the full forms of words spelt with capital letters; for example, "DCE" (District Chief Executive), "WAEC" (West Africa Examination Council) etc. Contractions are a form of abbreviation and mostly the letters from the middle of the full form of the word are omitted. They could be described as clippings or cuttings, for example, "can't" instead of "cannot". Initialisms or Semi-shortenings are the initial letters of words. However, the initial letters are pronounced as separate letters; for example, USA. Acronyms can be described as initialisms but for acronyms, they have become words in their own right and are pronounced as their short forms rather than their full form, for example, AIDS.

Alphanumeric conventions constitute one of the forms of how some abbreviations are formed; that is, the abbreviations are a combination of letters and numbers. For example, "b4 we meet 2moro, send de moni 4 me" - "before we meet tomorrow, send the money for me". It is becoming an up-to-date trend that a boundless number of abbreviations are now created by its users and generally, the recipients do comprehend them; for example, "De skul iz nt in sxtn" - "The school isn't in session".

The incorporation of abbreviations in SMSs is contingent on the relationship between the sender of the text and the receiver. An SMS which is delivered to an elderly person or a lecturer will be bereft of informal or unconventional abbreviations like " de", "kam", "gr8t"etc, quite dissimilar that which is directed to a colleague or an age mate.

\section{The Challenge}

Many lecturers have raised quite an appreciable number of concerns about the use of abbreviations, especially about the orthography used by the students of Kumasi Technical
University in their academic writing. As a Communication Skills lecturer who is very much fascinated by the accurate language use by students, 1 decided to probe deeper into the subject of unconventional abbreviations students employ in their SMS texting and consequently find out what meanings those abbreviations convey.

During most interactions with the students, one fathoms that quite a sizeable number of them are often in a dilemma as to which precise formal word or expression to use. Their expressions are densely jam-packed with a lot of informal words, which is typically expected when communicating with friends but time and again, the students are deficient as to where to draw the demarcation when it comes to a formal situation. When the spotlight is thrust on the issue of written discourse, it brings to attention many of these abbreviations practically created by the users (students) intended to lessen communication difficulties, which sip unknowingly into their writing. Some of these unconventional abbreviations are 'de' for 'the', 'bc' for 'because', ' $\mathrm{d} 8$ ' for 'date', just to mention a few. One cannot repudiate the fact that language is always in a perpetual state of evolution and sometimes these 'reconstructions' gradually metamorphose into a standard and accepted language. The greatest challenge is students are sometimes oblivious of the fact that they are using chat language in their academic discourse.

\section{LITERATURE REVIEW}

\section{The Genesis of SMS}

Short Message Service (SMS) is a text messaging component of phone, web or mobile communication. Standardized communication is the main component to follow in the exchange of short text message. Fixed line or mobile phone devices are the phone devices pertinent for short text messaging. The functioning of text message to mobile devices began in the early 1980s. Friedhelm Hillebrand and Bernand Ghillebaer developed the SMS concept in the France-German GSM cooperation in 1984. The GSM was optimized for telephone use as that was found to be its main application. Hillebrand (2010) was of the opinion that 160 characters were ample to express most messages. These characters can be in the form of text (alphanumeric) or binary non-text short message. The issue of the number of characters to use has furthered the rise of novel and devised abbreviations which is as a result of sometimes constrained time and space on the device. This occurrence makes texters ground-break into varied modes of texting. At the end of 2010, SMS had an estimated 3.5 billion active users or with about $80 \%$ of all mobile phone subscribers and was the most widely data application used(Portio Research, 2015). As of September 2014, global SMS messaging business is considered to be worth USD 100 billion and 50\% of all the revenue accrued is from SMS mobile messaging (Worldwide Portio Research).

\section{Benefits of SMS}

SMS usage covers a wide scope of varieties of people and one group is public health officials who access this applica- 
tion for health-related communication purposes. They send SMS texts to their patients to repetitively remind them of their scheduled meetings with their health givers and accordingly, the treatment to be given (Journal of the American Psychiatric Nurses'Association, 2014).

In distance learning, universities usually communicate with the students predominantly by post, though at times the information gets lost or takes too long a time to reach the students. The unreliability of the post method necessitated the use of SMS. This is to bridge the gap of contact between the university and the students owing to the fact that the message goes directly to the intended receiver (Institute for Continuing Education, University of South Africa, 2014).

In the wake of recent college shootings and threats of violence on campus, administrations have instigated the usage of the cell phone as solutions to deliver emergency text messages to students. This they have confidence in to reduce to the barest minimum, the impairment that could have occurred in an emergency situation (August 2008 EDUCAUSE Quarterly; Vol 31 no 3).

A command of texting seems to denote a broader facility for language use. According to a 2006 study, there is an indication that students who recurrently use a lot of SMS texts are able to swap over easily between text messaging and Standard English (The New York Sun, January 23, 2008).

\section{Some views about the use of SMS}

According to Sutherland (2002), since texting is a nippy way of transmitting information, abbreviation is the basis of it. In order for a texter to be able to transmit any information within a limited time and space, there is the need to employ the use of abbreviations. This assertion is corroborated by Crystal (2008) that text messages which have insertions of abbreviations are less than 20\%. Plester, Wood and Bell (2006) as cited in Crystal (2008) make a further exposition that research conducted divulges the fact that it is only students who have a well-founded and steady foundation in reading and vocabulary who are comfy using abbreviations and have comprehended the longer forms of the words and sentences they break down. Sutherland (2002) further argues that most educationists concede to the issue that texting disguises and conceals the effect of dyslexia, has a lot of poor spelling and is a weak penmanship for illiterates.

A recent USA Today Magazine Article(2008) entitled “Texting, Testing Destroys Kids' Writing Styles" appears to substantiate these claims quoting Jacqueline Ream, author of K.I.S.S., Keep It Short and Simple(2005). The article states that, These kids aren't learning to spell. They're learning acronyms and shorthand. Text messaging is destroying the written word. Students aren't writing letters:

they're typing into their cell phones one line at a time.

These kids aren't learning to spell. Feelings aren't communicated when you are texting. Emotions are sideways

smiley faces. Kids are typing shorthand jargons that aren't a complete thought. (p.8)

A counter idea by Crystal (2008) in his book Txting: The $G r 8 D b 8$, stipulates that
I do not see how texting could be a significant factor when discussing children who have real problems with literacy. If you have difficulty with reading and writing, you are hardly going to be predisposed to use a technology that demands sophisticated abilities in reading and writing. And if you start to text, 1 would expect the additional experience of writing a help rather than a hindrance. (p.157)

Several conceivable explanations which kindle a positive relationship between texting and literacy skills have been proposed by Plester et al $(2008,2009)$.One is that texting simply escalates one's exposure to the written discourse, which is a positive predicator of a learner's reading success. This is buttressed by Cipielewski and Stanovich (1992) who also opine that texting is one way or form through which a child is exposed to the written discourse in a much quicker way. A second possibility is that prospects are open for children to play with words through the act of texting, thus increasing their engrossment for traditional reading and spelling. The final clarification is that phonology is closely interrelated with the creation of text words and this has the propensity of enhancing children's awareness of the grapheme-phoneme (letter-sound) correspondence rules, which is an indispensable skill for traditional spelling and reading proficiency.

In furtherance of these explanations, Plester (2008) comments that a child's literacy skills are not affected adversely through text messaging and argues that rather, educators use it as a tool to increase the literacy of children. He further contends that the onus lies on teachers to help students manage text messaging and make the students cognizant of the differences between the language used in texting and that of Standard English. According to Plester\&Wood (2009), "It is clear also that texting does not contribute to the demise of pre-teen children's literacy" (p.18).Quite apart from a few scholars who maintain that texting has a negative effect on standard writing, spelling and grammar (Siraj\&Ullah, 2007), most studies conducted experimentally are of the positive opinion that texting does not proffer much of a threat to Standard English learning and teaching.

One such study is that conducted by the British Press (Fresco, 2008) that postulates that the reservations people have concerning the fact that text messaging may in one way or the other ruin the writing abilities of teenagers is unsubstantiated. They conducted an experiment for two years and established that youngsters are more literate than ever regardless of their use of texting.

According to Corker (2012) who analyzed 300 SMS messages posted to panel discussions on two local radio stations: Joy FM and Peace FM, it came to light that when people were disgruntled with happenings in Ghana, they often resorted to three basic types of complaint strategies in their SMSs sent to the radio stations: attacks, name-calling and down toners. The analysis disclosed that the complaints evidenced the face-threats of the texters, though some were marked by politeness.

It could be conjectured from the literature review above that there are wide-ranging views on the benefits and effects 
of SMS, and that there are diverse ways people come up with their own innovative means of texting. It is worthy of saying that quite a substantial number of studies have been done in SMS texting and issues that revolve around it. Although some attention has been given to various aspects of SMS text messaging, there is a gap in the research of linguistic and phonological aspects of SMS. This study proposes to bridge the gap by conducting a linguistic and phonological analysis of non-conventional abbreviations used by students of Kumasi Technical University and how frequently those abbreviations are used.

\section{Analytical Framework}

The framework for this study is based on Anjaneyulu's (2003) five methods of generating shortened words in SMS. The difference that this study anticipates to create is using "alphanumeric" instead of "hybrid" used by Anjaneyulu. The basis is to well-define to readers precisely what 'alphanumeric' is. The name 'alphanumeric' readily brings to mind the use of letters and numbers. Again, adhoc abbreviations were disregarded in this study owing to the fact that an unappreciative percentage of this type of abbreviation was used by the students and since it would not contribute significantly to the analysis, it was taken out of the working list. Subsequently, these methods of generating shortened words are adopted; (i) using letters, symbols or numbers to make the appropriate phonetic sound; (ii) dropping one or more letters; (iii) standard or adhoc acronyms and (iv) alphanumeric as a working list to analyze the SMSs collected.

The present study is quantitative in nature and mode. The population for the study is HND students of the Faculty of Business, comprising five departments. The departments are Accountancy, Computerized Accounting, Procurement and Supply Chain Management, Secretarial and Management Studies and Marketing. This faculty is preferred for the fact that most of the courses the students pursue encompass calculations and subsequently the tendency to use less written forms is high, though some of the departments are occupied with courses that necessitate more writing than calculations. Accordingly, it is anticipated that these students use a lot of abbreviations in their courses and thus, the study will have varieties of abbreviations to be examined.

\section{Data Collection and Methodology}

A corpus of 300 SMSs was gathered for this study and 200 were picked by purposive sampling for the analysis. The population of the study was stratified based on departments and the students were purposely selected from each strata. The stratified purposive sampling method was used to satisfy the purpose the researcher wanted to achieve. Palys (2008) opines that "the sample a researcher employs must be connected to the objectives he intends to achieve". This purpose matches the selection of students and excludes those that would not help the researcher to accomplish her objectives. According to Patton (1990), "the logic and power of purposive sampling lies in selecting information- rich cases for the study in depth" thus, forty SMSs were selected from each department, giving a totality of 200 SMSs.

\section{Department Distribution}

The department distribution of students from the five departments under the Faculty of Business involved in this research is presented in Table 1 below.

The selected departments signify departments that are predisposed to a lot of writing and use of calculations. Since this study has its emphasis geared towards finding out the variety of abbreviations used by students, there is the need to cut across different departments in order to accomplish that focus.

\section{RESULTS}

\section{ACCOUNTANCY DEPARTMENT}

COMPUTERISED ACCOUNTING DEPARTMENT PROCUREMENT\&SUPPLY CHAIN MANAGEMENT

\section{DEPARTMENT}

SECRETARIAL AND MANAGEMENTSTUDIES DEPARTMENT

\section{MARKETING DEPARTMENT}

The findings for this research have been divided into various categories. These include gender distribution and abbreviation distribution. The abbreviations will further be analyzed linguistically and phonologically.

Students of Computerized Accounting Department and the Accountancy Department of the Faculty of Business absorb themselves in the use of abbreviations. The corpus of data collected from the forty students encompassed more alphanumeric than abbreviations made up of letters. The intention for this assertion cannot be farfetched owing to the fact that most of the courses the students study involve figures and calculations. A few of the abbreviations used are "L8t (Late), 2moro (tomorrow), 9t (night), 9ce (nice), 3ice (thrice)", among others.

The use of these abbreviations apart from abetting one to write more within a short time facilitates the economic use

Table 1. Department distribution of the SMSs

\begin{tabular}{lc}
\hline Department & TOTAL \\
\hline Accountancy & 40 \\
Computerized accounting & 40 \\
Procurement \&aupply chain mgt & 40 \\
Secretarial and management studies & 40 \\
Marketing & 40 \\
TOTAL & 200 \\
Percentage & $100 \%$ \\
\hline
\end{tabular}

Table 2. Summary of frequency of abbreviations used

\begin{tabular}{lcc}
\hline Abbreviation type & Frequency & Percentage \\
\hline $\begin{array}{l}\text { Letters/symbols/numbers } \\
\text { making the appropriate } \\
\text { phonetic sound }\end{array}$ & 15 & 32.6 \\
Adhoc acronyms & 3 & \\
Alphanumeric & 18 & 6.52 \\
Dropping one or more letters & 10 & 39.13 \\
TOTAL & 46 & 21.73 \\
\hline
\end{tabular}


Table 3. Summary of frequency of abbreviations used

\begin{tabular}{lcc}
\hline Abbreviation type & Frequency & Percentage \\
\hline $\begin{array}{l}\text { Letters/symbols/numbers } \\
\text { making the appropriate } \\
\text { phonetic sound }\end{array}$ & 10 & 20 \\
Adhoc acronyms & 8 & \\
Alphanumeric & 24 & 16 \\
Dropping one or more letters & 8 & 48 \\
TOTAL & 50 & 16 \\
\hline
\end{tabular}

Table 4. Summary of frequency of abbreviations used

\begin{tabular}{lcc}
\hline Abbreviation type & Frequency & Percentage \\
\hline $\begin{array}{l}\text { Letters/symbols/numbers } \\
\text { making the appropriate } \\
\text { phonetic sound }\end{array}$ & 11 & 23.40 \\
Adhoc acronyms & 10 & \\
Alphanumeric & 13 & 21.27 \\
Dropping one or more letters & 13 & 27.65 \\
TOTAL & 47 & $100 \%$ \\
\hline
\end{tabular}

Table 5. Summary of frequency of abbreviations used

\begin{tabular}{lcc}
\hline Abbreviation type & Frequency & Percentage \\
\hline $\begin{array}{l}\text { Letters/symbols/numbers } \\
\text { making the appropriate }\end{array}$ & 20 & 31.74 \\
phonetic sound & & \\
Adhoc acronyms & 13 & 20.63 \\
Alphanumeric & 15 & 23.80 \\
Dropping one or more letters & 15 & 23.80 \\
TOTAL & 63 & 100 \\
\hline
\end{tabular}

of time and space for each text message sent. The students study how to account judiciously for every expenditure incurred and this is manifested in their use of abbreviations.

On the other hand, students of Secretarial Management Department opt for the use of letters as against numbers or figures. Since they are training to become secretaries who do more writing and make resourceful use of especially shorthand writing, using abbreviations is an element of their writing style. An appreciable number of their text messages do not encompass alphanumeric abbreviations and repeatedly abbreviations like "shud (should), hav (have), pls (please), frm (from), der (there), burfdae (birthday), knt (cant)", just to mention a few reflect in their text messages.

Procurement and Supply Chain Management students likewise the Marketing students use a combination of letters and numbers for abbreviations in their text messages. They make maximum application of alphanumeric and letters for abbreviations owing to the fact that the courses they are studying are geared towards a combination of theoretical work and calculations. Their preference reflects in the regular use of abbreviations like "4ever (forever), 4gt (forget), oda (other), W8t (wait), sam1 (someone), lemme (let me), beta (better), 2serus (too serious), 2wrds (towards), ker (care), just to list a few".
Table 6. Summary of frequency of abbreviations used

\begin{tabular}{lcc}
\hline Abbreviation type & Frequency & Percentage \\
\hline $\begin{array}{l}\text { Letter symbols/numbers } \\
\text { making the appropriate } \\
\text { phonetic sound }\end{array}$ & 18 & 33.96 \\
Adhoc acronyms & 10 & 18.86 \\
Alphanumeric & 15 & 28.30 \\
Omitting one or more letters & 10 & 18.86 \\
TOTAL & 53 & 100 \\
\hline
\end{tabular}

Table 7. Frequency and percentage of the abbreviations

\begin{tabular}{lcc}
\hline Type of abbreviation & Frequency & Percentage \\
\hline $\begin{array}{l}\text { Letters/symbols/numbers } \\
\text { making the appropriate } \\
\text { phonetic sound }\end{array}$ & 75 & 37.50 \\
Adhoc acronyms & 13 & \\
Alphanumeric & 41 & 6.5 \\
Omitting one or more letters & 71 & 20.5 \\
TOTAL & 200 & 35.5 \\
\hline
\end{tabular}

\section{Abbreviations Distribution}

The abbreviations students deliberately use show they are more inclined towards the use of more unconventional abbreviations than the conventional ones. From the SMSs collated from the five departments under the Faculty of Business, certain suppositions could be drawn. It is perceived that aside a few isolated cases, most of the abbreviations used are unconventional and seemingly toe the line of Anjaneyulu (2013) who postulates that SMS texting involves symbols or numbers to make the appropriate phonetic sound like $g r 8$ and some hybrids or alphanumeric abbreviations like $b 4$.From the corpus of SMSs, it is without uncertainty that a greater number of the abbreviations fall under the category of hybrids and the use of symbols and numbers which portray the appropriate phonetic sound. The pervasive unconventional abbreviations the students perpetually use form $60 \%$ of the corpus of SMS analyzed. The groupings of the various abbreviations can be discussed under the thematic areas thus; Linguistic Analysis and Phonological Analysis.

\section{LINGUISTIC ANALYSIS}

The description of language in terms of morphology, syntactic and semantic structures can be clarified as linguistic analysis. Morphology interests itself with words and the components of words, Syntax considers how words are put together to form sentences and Semantics contemplates the meaning that words and phrases invest into the meaning of sentences. Many speakers of language incorporate rules which they come by on their own into the languages they speak and that becomes some category of guidelines for those who want to learn a language or adopt a language.

Students in their bid to communicate with their friends quickly and with consideration to space for text messages choose their own words, phrases and sentences and that cre- 
ates unconventional abbreviations in the SMS they send. This section will concentrate on syntactic structures, the morphology of the abbreviations used and the semantics associated with the abbreviations.

From the above table, it could be realized that letters/ symbols/numbers which make the appropriate phonetic sound attain the highest frequency of 75 with a percentage of 37.5. This signifies that this abbreviation type is what the majority of the students have a preference for. The next commonly used abbreviation is omitting one or more letters with a frequency of $71(35.5 \%)$.Owing to the limited space one would have to type on a page, the tendency to omit one or two letters of a word in order to write more is immense.

Alphanumeric type of abbreviation has a percentage of 20.5 with a frequency of 41 . This involves the use of numbers and letters and with some of the students studying courses that make use of calculations, they will apparently opt for this form of abbreviation. Adhoc acronyms have the lowest frequency of $9(4.5 \%)$. This could be explained by the fact that students would want to make up their own abbreviations and not be too traditional, hence the less use of that type. Students are not too acquainted with Adhoc acronyms since just substituting a word with a letter would be something their recipients would find incomprehensible.

\section{Adhoc Acronyms}

These abbreviations could be described as Initialisms which often take the first letters of the original words and they become full words on their own. This is sparingly used by students because it becomes quite a challenge for the recipients to decipher the meaning associated with the acronym, especially when one is not very accustomed to the use of that acronym. Some of the acronyms sent by the students have been analyzed linguistically:

i) LOL - Laugh out loud (Imperative Sentence)

laugh- verb

out- adverbial

loud- adverb

ii) DW - Don't worry (Imperative, Assurance)

don't- verb+ not (negation)

iii) GBU- God bless you (wish)

God- noun

bless- verb

you- pronoun

iv) HBD- Happy birthday (wish)

happy- adjective

birthday- noun

v) ASAP-As soon as possible (Imperative, wish)

as- conjunction

soon- adverbial

as- conjunction

possible- adjective

It could be deduced from the few examples cited above that the various parts of speech have been merged to form the expressions and thus, generated the acronyms used by the students. In a well-structured sentence, the parts of speech are put together coherently to form a meaningful sentence. Communication is intended to carry a message across to a recipient who needs to imbibe the contents without any hindrances encountered. A cursory look at the examples of Adhoc acronyms presented above implies that they should be acronyms known by the recipient of the text. The user of the acronym should be assured that the receiver of the message is well versed with the acronyms. A combination of the parts of speech without recourse to the meaning it makes does not augur well for effective communication. Probably, an assertion can be made that that is why the frequency for this type of abbreviation was very minimal.

\section{Omission Of One Or More Letters}

The students create their own abbreviations by omitting a letter or more from the full word in a bid to write more on the backdrop of the limited space and to save time. In certain situations, when a letter or some letters are dropped from a word, ascertaining its meaning becomes a task. The elliptical form sometimes poses comprehension problems where the receiver is not conversant with that abbreviation. In terms of deriving meaning from these abbreviations, meaning is quite easy to decipher when just a letter is dropped and that does not affect the structure of the word significantly.

The idea behind most students using this is to make them type more words within a short spate of time. The students use the elliptical form depending on the relationship the sender has with receiver of the SMS. A student who communicates with a friend, colleague or age mate often deletes some of the letters of a word but in situations where the student communicates with an adult, there is lesser room for deletion of letters from words. This is basically to show formality with the adult recipient.

Omission of one or more letters is the highest type of abbreviation used by the students and it has a frequency of $35.5 \%$. This is so basically due to the fact that comprehension is quite unproblematic when just a letter is omitted and the structure is not greatly affected. Even in situations where more than one is omitted yet the structure is not affected, it still remains uncomplicated to decipher.

The following are the examples of the abbreviations involving the omission of one or more letters, which have been analyzed linguistically.

i) Hw old $\mathrm{r}$ u- (Question)

how-adverb

old- adjective

are- verb(present)

you- pronoun

ii) Wat hve 1 dan rong- (Question)

what- relative pronoun

have- auxiliary verb

1 - pronoun

wrong- adjective

iii) I prayed $4 \mathrm{u}$ tho- (Assurance)

1- pronoun

prayed- verb(past)

for- preposition

you- pronoun

though- conjunction

The letters omitted often does not upset the structure so much and consequently, meaning is not significantly impact- 
ed. An analysis could be deduced that after the omission of some of the letters, the 'new' word is in consonance with the phonetic sound of the original word and that helps to decipher the meaning of the word.

\section{PHONOLOGICAL ANALYSIS}

Clark et al (2007) describe phonological analysis as the conscious and predetermined use of sound to encode meaning in any language that is spoken by humans. The sounds that an original word conveys are what many students invest in the words and abbreviations they use in their SMS. They utilize the sound that is close at hand or just like the word itself which invariably results in the omission of some letters. They organize the sound in such a way that it performs the semantic function of the intended message put across. The abbreviations that fall under phonological analysis are alphanumeric and letters/symbols/numbers making the appropriate sound.

\section{Alphanumeric}

Alphanumeric type of abbreviation has a percentage of 20.5 with a frequency of 41 . This type of abbreviation is a hybrid of numbers and letters and since most of the students are pursuing courses involving calculations, the use of numbers comes quite easier to them thus, this type of abbreviation is also preferred. Most students are advocates of this type owing to the fact that the numbers are able to take up a lot of letters and therefore in sending an SMS to someone, it is not farfetched to say that alphanumeric is preferred.

The following are examples of alphanumeric type of abbreviation which have been analyzed phonologically.

i. $\mathrm{C}$ u2moro- tomorrow-/tə-mar-o/(transcribed form)

'2moro' is used by the students to mean 'tomorrow' owing to the fact that 'to' sounds almost like ' 2 ' and the 'morrow' like 'moro'. The way most students pronounce the word is exactly how the abbreviation is derived, howbeit not as the transcribed form of the word is.

ii. Am 4evrg8tful- forever grateful-/fə-rev-ər//grat-fəl/ (transcribed forms)

' 4 evr' is an abbreviation for 'forever' since in pronouncing the word, it gives the sound ' 4 ' and 'evr' is an ellipsis of 'ever'. The corresponding sounds accompanying the words help the students to derive the sounds they use as abbreviations.

iii. 9ce- nice-/nis/(transcribed form)

The pronunciation of the alphanumeric type of abbreviation reflects closely the sound of the actual word. The word 'nice' has the sound of the pronunciation of the figure 9 imbedded in the sound that accompanies the pronunciation of the word and 'ce' is similar to the sound of the ending of the word.

Letters/Symbols/Numbers making the appropriate phonetic sound

These abbreviations incorporate use of only letters, symbols or numbers or a combination of two or more of these but the definite aspect of this is that the abbreviations make an appropriate phonetic sound which corresponds to the orig- inal word. From the analysis made, it could be figured out that this type of abbreviation has the highest frequency of 75 with a percentage of 37.5 . This signifies that this type of abbreviation is what the majority of the students prefer to use.

Some examples of abbreviations are:

i. Anada baby! Gud tidings- another baby! Good tidings Another/ə-nə-thər/Good/gud

ii. U a 2 serious in lyf- you are too serious in life You/yu/are/er/too/tu/life/lif

A presumption could be made that the abbreviations the students use are closely related to the transcriptions of the actual words. This makes understanding of the abbreviations quite easy and most students prefer using them. Communication is not seriously impeded since the pronunciation of the words seems just like the actual words.

\section{IMPLICATIONS}

Almost every lecturer would aspire to see his students linguistically inclined, having the best of writing skills. The results and findings of this study divulge some implications which would have far-reaching repercussions for tertiary institutions, precisely technical universities, since that is the focus of the study. There is an erroneous belief especially among most technical university students that since their courses focus more on technical education, the emphasis on good writing skills should be relegated to the background. The demands of academic writing are not permissive with the use of unconventional abbreviations since those abbreviations are not known and accepted internationally. Unfortunately, this tendency is gradually seeping into the academic writings of tertiary students and it has to be nipped in the bud.

This study is therefore a wake-up call to students who have assimilated this informal way of communicating to discriminate between formality and informality in communication. The incessant use of these unconventional abbreviations could possibly affect the writing skills of these students. When these same students inhabit managerial positions and are mandated to submit reports, write memorandums and send notices, it would not be erroneous to conclude that some of these unconventional abbreviations might stray into these writings.

It is therefore pragmatic that more research would be geared in the direction of the effects of unconventional abbreviations in tertiary students' academic work.

\section{CONCLUSION}

This paper sought to examine the varieties of unconventional abbreviations used by students of some selected departments of Kumasi Technical University and the most frequently used ones. These SMSs were analyzed linguistically and phonologically. Purposive sampling was used to gather a corpus of 300 SMSs with 200 selected for analysis based on Anjaneyulu's (2013) five methods of generating shortened words. The study uncovered that $60 \%$ of the students used more unconventional SMSs principally because they appreciated inventing their own expressions due to the added advantage they benefitted from in terms of time and space 
limit. The most frequently and pervasive unconventional abbreviations used by the students were 'Hapi', 'de','thanx, tanx, tnx','sed', bday, burfdae','gud', 'skull', 'wat', 'iz'. The impact of the usage of these unconventional abbreviations could be further researched into.

\section{REFERENCES}

Anjaneyulu, T. (2013). A glossary: usage abbreviations of mobile phone SMS. et Cetera, 70(2), 141.

Analysis and forecasts for Mobile Messaging Worldwide Portio Research, Retrieved 14 June 2015.

Carrington, V. (2004). Texts and literacies of the Shi JunRui. British Journal of the Sociology of Education, 215-228.

Clark et al. (2007). An introduction to Phonetics and Phonology ( $3^{\text {rd }}$ ed) Massachusetts, USA; Oxford, UK; Victoria, Australia; Blackwell Publishing ISBN 978-1-4051-3083-7

Crystal, D. (2006). Language and the internet, Engaging and Provocative Nature(2nded) Cambridge.

Crystal, D. (2008). Texting; friend or foe? The Linguist,8-11.

Crystal D. (2008). Texting. Oxford University Press

DeJonge, S., \& Kemp N. (2010). Text-messaging abbreviations and language skills in high school and university students. Journal of Research,doi:101111 \j.1467-9817.2 010.01466X.

Fresco(2005,Oct 13) Texting Teenagers are proving $\mathrm{u}$ are more literate than ever before, Times on-line, Retrieved May 23,2016.

Hillebrand et al (2010). SMS: The Creation of Personal Global Text Messaging, Wiley.
Ling, R. (2006). The Sociolinguistics of SMS. An Analysis of SMS Use by a random sample of Norwegian, London Observer (March 7, 2004)

Palys, T, (2008). Purposive Sampling. In L.M.Given (Ed.) The Sage Encyclopedia of Qualitative Research Methods (Vol 2) Sage: Los Angeles,pp 697-8

Patton M.Q. (1990). Qualitative Evaluation and Research Methods $2^{\text {nd }}$ edn.Sage, Newbury Park, California

Plester et al. (2009). Exploring the relationship between children's knowledge of text message abbreviations and school literacy outcomes. British Journal of Developmental Psychology 27,145-161.

Ream, J. (2005). K.I.S.S. Keep It Short and Simple, Bothell, A: Book Publishers Network

Rosen et al (2010). The Relationship between "Textisms" and Formal and Informal Writing Among Young Adults. Communication Research 420-440.

Schatzman, D., \& Strauss, A.L (1973). Field Research Strategies for a Natural Sociology. Prentice Hall, Englewood Cliffs, New Jersey.

Short, T. (2007). Gr8T xpectations: the creativity of text spelling, English Drama Media, June 2007, 21-26.

Sutherland. Mobile Phones Cn u txt(11 Nov 2002) Retrieved 23 May 2016.

The New York Sun, January 23, 2008

The New York Sun, April 24, 2001

The Text Message Turns 20 (December 3, 2012):CNN

Wincharles, C. (2012). Complaint Strategies of SMS Texts in the contexts of Radio Panel Discussions in Ghana 2012 University Printing Press, Cape Coast. 